\title{
Correction to: Direct quantitation of tenofovir diphosphate in human blood with mass spectrometry for adherence monitoring
}

\author{
Fan $\mathrm{Pu}^{1} \cdot$ Sangeeta Pandey ${ }^{1} \cdot$ Lane R. Bushman $^{2} \cdot$ Peter L. Anderson $^{2} \cdot$ Zheng Ouyang $^{1,3} \cdot$ R. Graham Cooks ${ }^{1}$
}

Received: 10 January 2020 / Accepted: 10 January 2020 / Published online: 18 January 2020

(C) Springer-Verlag GmbH Germany, part of Springer Nature 2020

\section{Correction to: Analytical and Bioanalytical Chemistry} https://doi.org/10.1007/s00216-019-02304-0

Unfortunately, after online publication, a formatting mistake was found in Table 1 (Chemical structures and MRM transitions used for quantitation). The original article has been corrected.

The online version of the original article can be found at https://doi.org/ $10.1007 / \mathrm{s} 00216-019-02304-0$

Peter L. Anderson

peter.anderson@cuanschutz.edu

$\triangle$ R. Graham Cooks

cooks@purdue.edu

1 Department of Chemistry, Purdue University, 560 Oval Drive, West Lafayette, IN 47907, USA

2 Skaggs School of Pharmacy and Pharmaceutical Sciences, University of Colorado Denver, 12850 East Montview Blvd., Aurora, CO 80045, USA

3 Department of Precision Instrument, Tsinghua University, Haidian District, Beijing 100084, China 